\title{
Experimental Study of the Effect of Disorientation Angle on the Deformation of Carbon Composite Plates
}

\author{
Olga BITKINA ${ }^{1}$, Jang-Ho LEE $^{2 *}$, Elena DARLINGTON ${ }^{3}$ \\ ${ }^{1}$ CUWES, Kunsan National University, Kunsan, Jeonbuk, 573-701, South Korea \\ ${ }^{2}$ School of Mechanical and Automotive Engineering, Kunsan National University, Kunsan, Jeonbuk, 573-701, South \\ Korea \\ ${ }^{3}$ WMG, International Manufacturing Centre, The University of Warwick, Coventry, CV4 7AL, United Kingdom \\ cross ${ }^{\text {ref }}$ http://dx.doi.org/10.5755/j01.ms.22.2.12932
}

Received 20 August 2015; accepted 24 January 2016

\begin{abstract}
The disorientation angle, a technological error in the manufacture of carbon composite materials, is the most important determinant of deviation of the obtained surface shape from the planned shape. Elimination of these defects results in additional time and financial costs. Therefore, this study examined the influence of the disorientation angle experimentally using carbon plastic (KMU-41) composite plates measuring $300 \times 300 \mathrm{~mm}$ with different basic structures such as 0/45/-45/90/90/-45/45/0;0/0/60/-60/-60/60/0/0;0/30/-30/90/90/-30/30/0. Plates were manufactured at a curing temperature of $175^{\circ} \mathrm{C}$ and cooled to room temperature $\left(23^{\circ} \mathrm{C}\right)$. Fibers were pre-tensioned; the tension was removed after curing. The difference between the curing temperature and room temperature caused thermal stress and deformation in the material structure. This was examined together with the effect of the disorientation angle. Experimental results for composite plate hogging as a function of the disorientation angle and thermal load were analyzed for different structures.

Keywords: carbon composite deformation, disorientation angle, fiber tension, layered structures, thermal residual stresses.
\end{abstract}

\section{INTRODUCTION}

The disorientation angle $(Q)$ of composite material layers and the thermal load contributes to the emergence of additional material deformation. To improve the manufacturing process and prolong the life of composite constructions, it is necessary to analyze the influence of the disorientation angle on the stress-strain state of composite structures, while considering the thermal load. Much research has examined the effects of the stacking sequence, material composition, and temperature on the mechanical behavior, deformation, and destruction of composite materials. For example, studies have investigated the stacking sequence and its effect on the forming behavior of stacked prepreg; the deformation and failure behavior of composites consisting of multiple alternating layers of a brittle, ductile amorphous thermoplastic polymer, which is controlled by the interaction between crazing and shear banding and displays a brittle-to-ductile transition depending on the composition; the main damage mechanisms of thermoset and thermoplastic composites with fatigue loads; the influence of interface damage on the macroscopic elastic stiffness and mechanical strength of composites; and the rate and low temperature dependencies of the viscoelastic behavior of the composites [1-6].

These studies showed the influence of different factors on composite deformation, but did not sufficiently resolve the influence of technological error on the stress-strain state. Therefore, we examined the influence of

\footnotetext{
* Corresponding author. Tel.: +82-63-469-4869; fax: +82-63-469-4727. E-mail address: jangho@kunsan.ac.kr (J.H. Lee)
}

technological error in the form of the disorientation angle on composite deformation experimentally.

\section{EXPERIMENT, RESULTS, AND ERROR OF MEASUREMENT}

In the manufacture of thin laminated composite plates, the structural element layers are glued together during the curing process with practically no slippage in any direction, i.e., the panel layers contact each other with perfect adhesion. Consequently, while cooling from the curing temperature $\left(120-180{ }^{\circ} \mathrm{C}\right)$ to ambient temperature $\left(23^{\circ} \mathrm{C}\right)$, adjacent layers become deformed, as characterized by anisotropic thermoelastic properties. Residual technological stresses and deformation arise in the structure elements during manufacturing, due to randomly oriented or heterogeneous layers of the fibrous composites used. These stresses and deformations define the initial stress state and geometric accuracy of the composite materials. Note that multilayered composites are usually manufactured in such a way that for each layer located on one side of the median plane of a composite panel, the thickness and orientation of the fibers correspond to an equidistant layer with the same properties on the opposite side of the median plane. Such composites, referred to as symmetrical composites, have a coefficient of membranebending stiffness characterizing their flexibility that is equal to 0 . If the composite symmetry is broken for at least one pair of layers, then the resulting layered composite panel is asymmetric, i.e., the coefficients of membranebending stiffness are not 0 and the membrane-bending relations can be obtained as a result of mechanical and thermal loads in the composite material. This case has not 
been studied sufficiently that we can see from the previous work [1-6] and additional theoretical and experimental research is needed, especially for structures with hard kinematic limitations for the final workpiece geometry. An evaluation of the characteristics of the stress-strain state of asymmetric laminated composites as a function of the disorientation angles of the composite layers enables understanding of the basic laws of deformation of the composites due to thermal stress. During the curing process, residual thermal stresses arise in a composite due to different values of the thermal expansion coefficient in the longitudinal and transversal directions. The residual macro-stresses can be obtained using the theory of multilayered composites, which considers these thermal stresses. These stresses should be calculated and analyzed, including stresses from external loads. Otherwise, the multilayered composite can be destroyed at considerably lower stresses than calculated, if the technological residual stresses are not included. Interlayer cracks initiated by the residual stresses can be observed, such as in high-modulus fibrous carbon composite materials. This problem is important and research should evaluate the impact of technological errors and factors, such as the composite thickness, boundary condition asymmetry, technological residual stresses, and disorientation angle of layers on the stress-strain state of structures.

This study examined the simultaneous influences of the disorientation angle and thermal stresses on composite plate deformation. In experiments, square carbon plastic composite panels measuring $300 \times 300 \mathrm{~mm}$ and $h=1.04$ $\mathrm{mm}$ in thickness were examined (Fig. 1). These plate dimensions were used to satisfy the condition of Thin Plate Theory, where side length-to-thickness ratio of composite plate should be equal or less than $1 / 20$. In this case the shear stresses can be ignored during analysis.

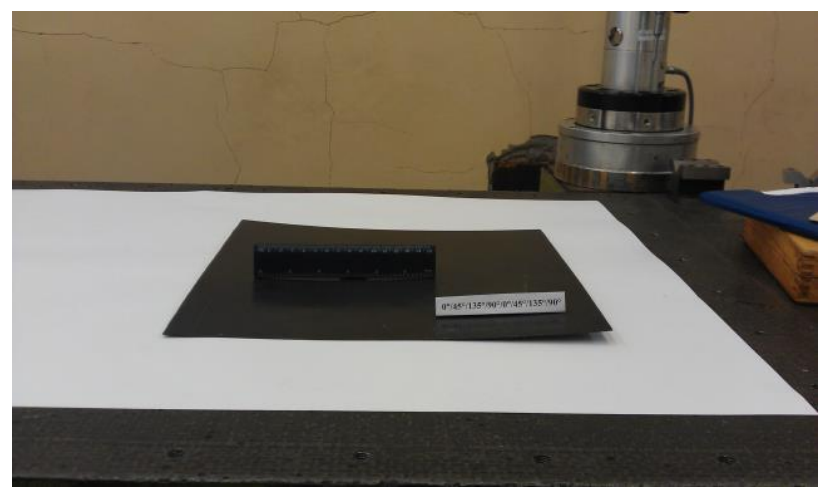

Fig. 1. Photograph of a carbon composite plate

The plates were not bound at the edges (free boundary conditions). Also, the plates were allowed to cool naturally to room temperature $\left(23^{\circ} \mathrm{C}\right)$ after direct molding at $175^{\circ} \mathrm{C}$. The panel became deformed as a consequence of the temperature differences (thermal stresses) and material characteristics. We studied composite structures made with oblique or a combination of longitudinal-transverse and oblique composite layers. Each layer of the plate was $0.13 \mathrm{~mm}$ thick and made from carbon plastic (KMU-41), whose properties are listed in Table 1.

The panels were manufactured from carbon composite KMU-4l, which is based on $L U-P$ carbon fiber and $E N F B$ epoxy matrix resin, in compliance with official recommendations for the manufacture of carbon fiberreinforced composite [7].

Carbon tape was impregnated using a vertical impregnating machine at a rate of $25-30 \mathrm{~m} / \mathrm{h}$, at temperatures varying from $40-70 \pm 5^{\circ} \mathrm{C}$ over the height of the impregnating machine tower.

Table 1. Properties of the carbon plastic

\begin{tabular}{|c|c|c|c|}
\hline Properties & $\begin{array}{c}\text { Elastic modulus, } \\
\text { E, GPa }\end{array}$ & $\begin{array}{c}\text { Shear modulus, } \\
\text { G, GPa }\end{array}$ & Poisson's ratio \\
\hline $\begin{array}{c}\text { Carbon fiber } \\
\text { (LU-P) }\end{array}$ & 250 & 100 & 0.25 \\
\hline $\begin{array}{c}\text { Epoxy matrix } \\
\text { (ENFB) }\end{array}$ & 3 & 1 & 0.35 \\
\hline
\end{tabular}

The impregnated carbon tape was dried and then was wound on a receiving shaft with a separating layer of cellophane or polyethylene film to obtain the prepreg roll. The roll was placed on a cutting table and sliced into layered samples. Then, the layered samples were stacked into semifinished products that were fed into a cold molding machine after preparatory work. The prepared semifinished products were cooled to room temperature $\left(23{ }^{\circ} \mathrm{C}\right.$ ) after direct curing at $175^{\circ} \mathrm{C}$ (Table 2) to make composite sheets. To obtain plates with the required dimensions, composite sheets were cut with a diamond wheel [8].

Table 2. Steps in the curing process [8]

\begin{tabular}{|c|c|}
\hline № & Curing step \\
\hline 1 & Heat to $80 \pm 5^{\circ} \mathrm{C}$ for at least $20 \mathrm{~min}$ \\
\hline 2 & Heat to $100 \pm 5^{\circ} \mathrm{C}$ for at least $20 \mathrm{~min}$ \\
\hline 3 & Heat to $110 \pm 5^{\circ} \mathrm{C}$ for at least $10 \mathrm{~min}$ \\
\hline 4 & Heat to $165 \pm 5^{\circ} \mathrm{C}$ for at least 20 min \\
\hline 5 & Hold at $170 \pm 5^{\circ} \mathrm{C}$ for $6-8$ hours \\
\hline 6 & Cool to $60 \pm 5^{\circ} \mathrm{C}$ at no less than $30^{\circ} \mathrm{C}$ per hour \\
\hline 7 & Cool to $\mathrm{ca} .23^{\circ} \mathrm{C}$ (no fixed time) \\
\hline
\end{tabular}

When manufacturing the composite plates, a customdesigned device was used for pre-tensioning the composite fibers [9]. This device (Fig. 2) consisted of a load frame with paired holders on opposite sides for attaching the composite plate and tensioning the fibers to a predetermined value.

The tension was controlled using calibrated springs, which maintain the tension at a constant level during heating and cooling. The tests were conducted on composite plate samples with fibers tensioned to $K_{H B}=0.6$. Tensioning the fibers is a manufacturing operation that is used to increase the load-carrying capability of structures. The level of fiber tension is determined by the fiber tension coefficient $\left(K_{H B}\right)$, which ranges from 0 to 1 , as given by the following equation:

$K_{\mathrm{HB}}=\varepsilon_{\mathrm{H}}{ }^{\mathrm{k}} / \varepsilon_{\mathrm{B}}{ }^{\mathrm{k}}$,

where $\varepsilon_{\mathrm{H}^{\mathrm{k}}}$ is the deformation of the $k^{\text {th }}$ layer due to tension; $\varepsilon_{\mathrm{B}}{ }^{\mathrm{k}}$ is the tolerable deformation of the $k^{\text {th }}$ layer.

The plate deformation was quantified using a laser tracker (API tracker 3-40, Automated Precision; measurement accuracy $\pm 0.005 \mathrm{~mm}$ ) with a manual scanning head placed on the plate at point B (Fig. 2) at coordinates $x=50 \mathrm{~mm}, y=50 \mathrm{~mm}$. The hogging of the test samples was measured using the manual scanning head of 
the laser tracker. The panel was aligned to determine the base coordinate system relative to the tracker. Using manual scanning, the measurement point was fixed on the composite panel. Fig. 3 outlines the measurement process [8].

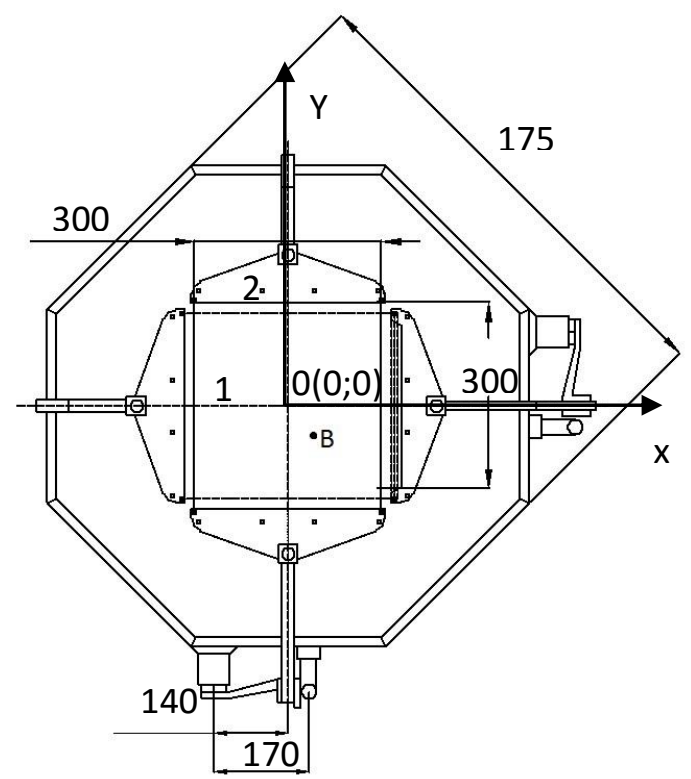

Fig. 2. Fiber-tensioning device: 1) the plate being tested; 2 ) one of the four holders [9]

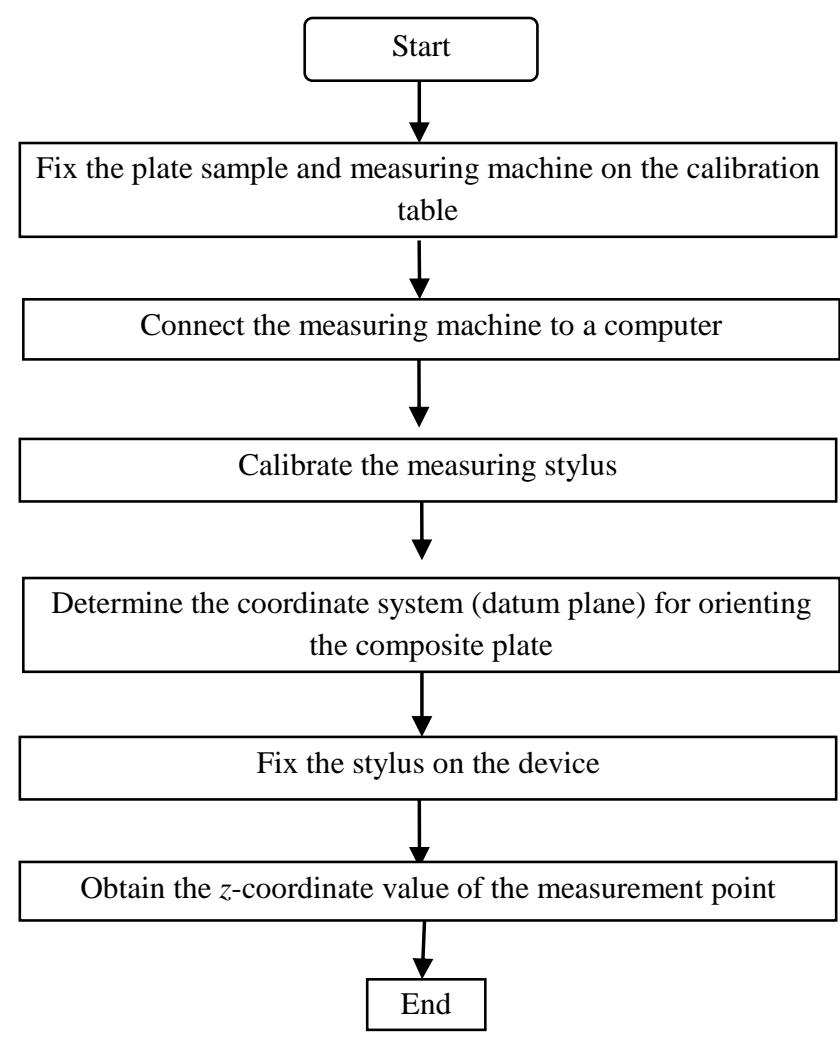

Fig. 3. Measurement sequence

Three groups of composite structures were studied based on the oblique layers at $30^{\circ}, 45^{\circ}$, and $60^{\circ}$. Table 3 shows the hogging at point $\mathrm{B}$ for these groups, with the measurement errors and percentage ratio of hogging $(W)$ to plate thickness $(h)$.

The measurement errors of single results were calculated using Eq. 2.
$\varepsilon_{\mathrm{D}}=\Delta D / D \cdot 100 \%$,

where $\Delta D= \pm 0.005 \mathrm{~mm}$ is the accuracy of the measurement equipment, and $D$ is the measured value.

This method of calculating the measured errors was chosen because a hogging result was obtained once for each case and was measured directly, i.e., the laser tracker gives the hogging result directly without any additional calculation [10].

The average measurement error was $5.3 \%$. In Case 8 (Table 3), the error was $25 \%$, which can be explained by scale dependency, i.e., the error increased with the amount of hogging, and for smaller hogging values, which were evaluated in our research (Case 8), the error was the highest.

The results indicated that the test has sufficient accuracy and can be used to make fundamental conclusions about the influence of the disorientation angle on the deformation of carbon composites.

Table 3. Hogging results and measurement errors (bold indicates a disoriented layer)

\begin{tabular}{|c|c|c|c|c|c|c|}
\hline Group & Case & Structures & $Q,^{\circ}$ & $\begin{array}{c}\text { Hogging } \\
W, \mathrm{~mm}\end{array}$ & Error, \% & $\begin{array}{c}\text { Ratio } \\
W / h, \%\end{array}$ \\
\hline \multirow{4}{*}{1} & 1 & $\begin{array}{c}0 / \mathbf{3 0} /- \\
30 / 90 / 90 /- \\
30 / 30 / 0\end{array}$ & 0 & 0.002 & - & 0.19 \\
\hline & 2 & $\begin{array}{c}0 / 29 /- \\
\text { 29/90/90/- } \\
30 / 30 / 0\end{array}$ & 1 & 0.062 & 8 & 5.96 \\
\hline & 3 & $\begin{array}{c}0 / 27 /- \\
27 / 90 / 90 /- \\
30 / 30 / 0\end{array}$ & 3 & 0.185 & 3 & 17.79 \\
\hline & 4 & $\begin{array}{c}0 / 24 /- \\
\text { 24/90/90/- } \\
30 / 30 / 0\end{array}$ & 6 & 0.379 & 1 & 36.44 \\
\hline \multirow[b]{2}{*}{2} & 5 & $\begin{array}{c}0 / 0 / \mathbf{6 0} /- \\
\mathbf{6 0} /- \\
60 / 60 / 0 / 0\end{array}$ & 0 & 0.001 & - & 0.096 \\
\hline & 6 & $\begin{array}{c}0 / 0 / \mathbf{5 3} /- \\
\mathbf{5 3} /- \\
60 / 60 / 0 / 0\end{array}$ & 7 & 0.179 & 3 & 17.21 \\
\hline \multirow{4}{*}{3} & 7 & $\begin{array}{c}0 / 45 /- \\
45 / 90 / 90 /- \\
45 / 45 / 0\end{array}$ & 0 & 0 & - & - \\
\hline & 8 & $\begin{array}{c}0 / 46 /- \\
46 / 90 / 90 /- \\
45 / 45 / 0\end{array}$ & 1 & 0.020 & 25 & 1.92 \\
\hline & 9 & $\begin{array}{c}0 / 48 /- \\
48 / 90 / 90 /- \\
45 / 45 / 0\end{array}$ & 3 & 0.050 & 10 & 4.81 \\
\hline & 10 & $\begin{array}{c}0 / \mathbf{4 0} /- \\
40 / 90 / 90 /- \\
45 / 45 / 0\end{array}$ & 5 & 0.143 & 3 & 13.75 \\
\hline
\end{tabular}

\section{DISCUSSION OF THE RESULTS}

The analysis conducted in this paper is useful for understanding the general principles of composite structure deformation. The results provide information about how control of the disorientation angle influences structure configuration, in accordance with predetermined technical requirements for composite constructions. This control is very important for most composite structures, such as for 
aerospace structures consisting of flat elementary composite plates.

From a practical perspective, the plates studied had eight layers because structures with eight layers are used in many fields, such as engineering, aviation, aerospace, and wind turbines. Table 3 shows that the minimum ratio of hogging $(W)$ to thickness $(h)$ of the composite plate corresponds to the non-disorientation angle in each structure group (Cases 1, 5, and 7). Despite symmetric structures with a disorientation angle of $0^{\circ}$, Cases 1 and 5 show a small amount of hogging, although it is negligible because the hogging/plate thickness ratio is less than $0.2 \%$. The main reason for the small amount of hogging is that the symmetric layers are skewed structures with carbon fibers at angles of $30^{\circ}$ and $60^{\circ}$ rather than a balanced angle of $45^{\circ}$. As shown in Table 3 , severe hogging can occur with a disorientation angle of $1^{\circ}$, as shown by the hogging/thickness ratios of $6 \%$ in Case 2 and $1.9 \%$ in Case 8 .

Fig. 4 plots the disorientation $(Q)$ and hogging in Table 3 for the composite structures with layer orientations of $0 / 30^{\circ}, 0 / 60^{\circ}$, and $0 / 45^{\circ}$.

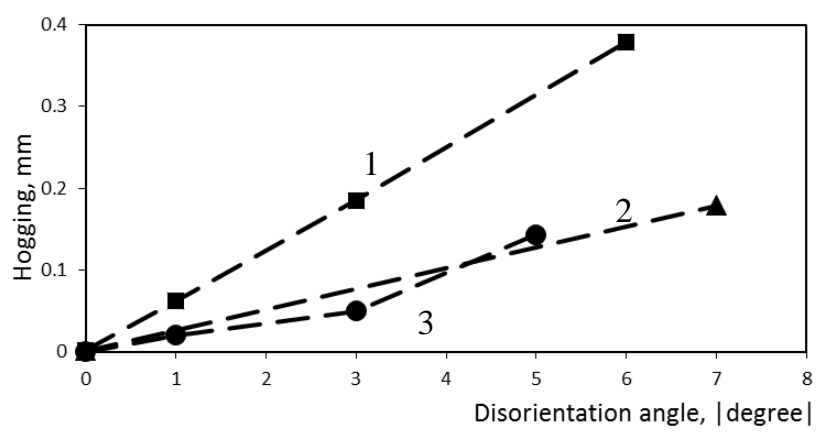

Fig. 4. Relationship between hogging and disorientation angle for the basic composite structures: $1-0 / 30 /-30 / 90 / 90 /-$ $30 / 30 / 0 ; \quad 2-0 / 0 / 60 /-60 /-60 / 60 / 0 / 0 ; \quad 3-0 / 45 /-45 / 90 / 90 /-$ $45 / 45 / 0)$

As Fig. 4 shows, increasing of the disorientation angle increased the deformation of the composite structures, because the disorientation angle disrupts the symmetry of the composite layered plates. This trend is also shown in our previous work [8], and other [11] in which various angles of the fiber orientation on a composite layer cause the different composite deformation. In those studies, the symmetric structure also has a value closer to zero in the deformation.

In our study, the membrane-bending relations resulted from the mechanical and thermal loads in the composite material. Additional thermal loads increase the thermal stress, which increases the deformation.

In the test results of Group 3, the change of $\mathrm{W} / \mathrm{h}$ ratio for the disorientation angle increase from $3^{\circ}$ to $5^{\circ}$ shows about 2.5 times, which is the similar level of hogging growth to the result of previous study with similar kind of structure [8].

Both test group of 1 and 3 have the similar combination structure of longitudinal-transverse and oblique composite layers as in Table 3. However, it is shown that the more skewed oblique structure with an angle of $30^{\circ}$ in Group 1 cause more hogging than the Group 3 with balanced oblique angle of $45^{\circ}$ as shown in
Fig. 4. Although Group 2 has a more oblique structure in the plate layering than Group 3, Groups 2 and 3 show similar levels of hogging because the layers angled at $60^{\circ}$ are balanced by the outer symmetric double layers in the longitudinal direction $\left(0^{\circ}\right)$.

\section{CONCLUSIONS}

This experimental study investigated square carbon plastic composite plates measuring $300 \times 300 \mathrm{~mm}$ under free boundary conditions (no attached edge) after cooling following direct curing. Using a laser tracker, we measured the hogging of symmetric composite structures with oblique layers and a combination of longitudinaltransverse and oblique composite layers. The findings were as follows:

1. The hogging increased markedly with the disorientation angle of the carbon fibers in a layer, although the base structure of the composite was symmetric with respect to the median plane of the composite plate.

2. Comparing composites with a combination of longitudinal-transverse and oblique layers, much more hogging occurred when the layers had a skewed oblique structure with an angle of $30^{\circ}$ (Group 1) versus a balanced oblique angle of $45^{\circ}$ (Group 3 ).

3. The composites with outer symmetric double layers in the longitudinal direction $\left(0^{\circ}\right.$; Group 2$)$ had a similar level of hogging to the combined oblique structure (Group 3), although the former had a pure oblique structure in the plate layering.

These results are applicable to industrial production because eight-layer carbon composite structures have many uses (engineering, aviation, wind turbine blades, aerospace, etc.) and the range of disorientation angles studied (from $0^{\circ}$ to $7^{\circ}$ ) are the most common technological error during the manufacture of composites.

The results can also be used to assign tolerances regarding the disorientation angle in actual manufacturing and for selecting the appropriate type of composite structure to reduce deformation. Finally, these test results can be used to validate numerical studies of composite plate hogging.

\section{Acknowledgments}

This study was partially supported by the Korean Energy and Technology Evaluation and Planning (KETEP) grant (Grant Nos. 20143010024330 and 20144030200590 ) from the Korean Ministry of Trade, Industry and Energy.

\section{REFERENCES}

1. Larberg, Y., Åkermo, M. In-Plane Deformation of Multilayered Unidirectional Thermoset Prepreg - Modelling and Experimental Verification Composites Part A: Applied Science and Manufacturing 56 2014: pp. 203-212. http://dx.doi.org/10.1016/j.compositesa.2013.10.005

2. Seelig, T. Computational Modeling of Deformation Mechanisms and Failure in Thermoplastic Multilayer Composites Composites Science and Technology 68 2008: pp. $1198-1208$. 
3. Jollivet, T., Peyrac, C., Lefebvre, F. Damage of Composite Materials Procedia Engineering 66 2013: pp. 746-758.

4. Jin, C.F., Zhu, Q.Z., Shao, J.F. A Numerical Analysis of Interface Damage Effect on Mechanical Properties of Composite Materials Mechanics Research Communications 62 2014: pp. 18-24.

5. Berthe, J., Brieu, M., Deletombe, E., Portemont, G. Temperature Effects on the Time Dependent Viscoelastic Behaviour of Carbon/Epoxy Composite Materials: Application to T700GC/M21 Materials \& Design 62 2014: pp. 241-246.

6. Cricrì, G., Luciano, R. Homogenised Properties of Composite Materials in Large Deformations Composite Structures 103 2013: pp. 9-17.

7. Catalog of carbon materials (VIAM) http://www.catalog.viam.ru/catalog/t2105/ugleplastik-kmu4l-2m 18 August 2015.
8. Bitkina, O., Kang, K.W., Lee, J.H. Experimental and Theoretical Analysis of the Stress-strain State of Anisotropic Multilayer Composite Panels for Wind Turbine Blade Renewable Energy 79 2015: pp. 219-226.

9. Bitkina, O., Lee, J.H., Darlington, E. Effect of Fiber Tension on the Deformation of a Carbon Composite Plate for Space Radio Telescopes Aerospace Science and Technology 45 2015: pp. 99-103.

10. Elements of theory of measurement and errors http://www.in-nov.ru/do/fizika/metrologia.pdf 18 January 2016.

11. Patel, V., Shah, D.B., Joshi, S.J. Determination of Deformation of Glass Epoxy Plate under Uniformly Distributed Loading Condition International Journal of Research and Scientific Innovation 1(8) 2014: pp. $482-487$ 